\title{
Tris(2-ethylhexyl) trimellitate (TOTM) a potential reference fluid for high viscosity. Part I: Viscosity measurements at temperatures from (303 to 373) K and pressures up to $65 \mathrm{MPa}$, using a novel vibrating-wire instrument
}

\author{
J.C.F. Diogo ${ }^{a}$, Helena M.N.T. Avelino ${ }^{\mathrm{a}, \mathrm{b}}$, Fernando J.P. Caetano ${ }^{\mathrm{a}, \mathrm{c}, *}$, \\ João M.N.A. Fareleira ${ }^{\mathrm{a}, * *}$ \\ a Centro de Química Estrutural, Instituto Superior Técnico, Universidade de Lisboa, Av. Rovisco Pais, 1049-001 Lisbon, Portugal \\ ${ }^{\mathrm{b}}$ Instituto Superior de Engenharia de Lisboa, Departamento de Engenharia Química, R. Conselheiro Emídio Navarro, 1, 1959-007 Lisbon, Portugal \\ ' Universidade Aberta, R. da Escola Politécnica, 147, 1269-001 Lisbon, Portugal
}

\section{A R T I C L E I N F O}

\section{Article history:}

Received 26 June 2014

Received in revised form 30 September 2014

Accepted 3 October 2014

Available online 8 October 2014

\section{Keywords:}

Reference

Viscosity

Vibrating wire

High pressure

Tris(2-ethylhexyl) trimellitate

\begin{abstract}
A B S T R A C T
The article reports viscosity measurements of compressed liquid tris(2-ethylhexyl) trimellitate or 1,2,4Benzenetricarboxylic acid, tris(2-ethylhexyl) ester (TOTM) which is an important plasticizer in the polymer industry and has wide applications as a lubricant. Nevertheless, the main motivation for the present work is to propose TOTM as a plausible candidate for an industrial viscosity reference fluid for high viscosity, high pressure and high temperature. This kind of reference fluid is presently on demand by oil industries and the International Association for Transport Properties is developing efforts aiming to select appropriate candidates and to establish the corresponding reference data.

The viscosity measurements were performed with a novel vibrating wire sensor. The new instrument was designed for operation at high pressures (up to $100 \mathrm{MPa}$ ) and temperatures up to $373 \mathrm{~K}$. The present measurements were obtained using the vibrating wire sensor in the forced oscillation or steady-state mode of operation. The viscosity measurements were carried out up to $65 \mathrm{MPa}$ and at six temperatures from (303 to 373$) \mathrm{K}$.

The viscosity results were correlated with density, using a modified hard-spheres scheme. The root mean square deviation of the data from the correlation is $0.53 \%$ and the maximum absolute relative deviation was less than $1.7 \%$. The expanded uncertainty of the present viscosity results, at a $95 \%$ confidence level, is estimated to be less than $\pm 2 \%$ for viscosities up to $68 \mathrm{mPa}$ s, less than $\pm 2.6 \%$ for viscosities between (69 and 268) $\mathrm{mPa}$ s and less than $\pm 3 \%$ for higher viscosities.

The TOTM density data necessary to compute the viscosity results were measured using a vibrating Utube densimeter, model DMA HP and are described in part II of the present work.

No literature data above atmospheric pressure could be found for the viscosity of TOTM. As a consequence, the present viscosity results could only be compared upon extrapolation of the vibrating wire data to $0.1 \mathrm{MPa}$. Independent viscosity measurements were performed, at atmospheric pressure, using an Ubbelohde capillary in order to compare with the vibrating wire results, extrapolated by means of the above mentioned correlation. The two data sets agree within $\pm 1 \%$, which is commensurate with the mutual uncertainty of the experimental methods. Comparisons of the literature data obtained at atmospheric pressure with the present extrapolated vibrating-wire viscosity measurements have shown an agreement within $\pm 2 \%$ for temperatures up to $339 \mathrm{~K}$ and within $\pm 3.3 \%$ for temperatures up to $368 \mathrm{~K}$. (c) 2014 Elsevier B.V. All rights reserved.
\end{abstract}

Abbreviations: CAS, chemical abstracts service; CRF, certified reference fluid; DEHP, di(2-ethylhexyl) phthalate; DIDP, diisodecyl phthalate; DVS, deepwater viscosity

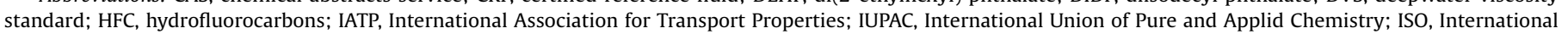

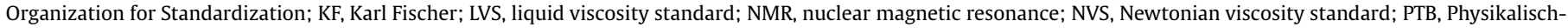

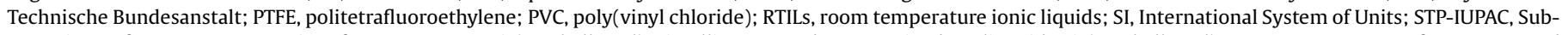

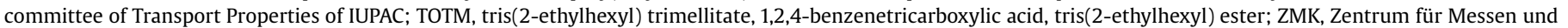
Kalibrieren.

* Corresponding author. Tel.: +351 218419060 .

** Corresponding author. Tel.: +351 218419265.

E-mail addresses: Fernando.Caetano@uab.pt (F.J.P. Caetano), j.fareleira@tecnico.ulisboa.pt (J.M.N.A. Fareleira). 


$\begin{array}{ll}\text { Nomenclature } \\ \\ \text { Symbols } \\ a_{0} \quad \text { fitting parameter of Eq.id=6\#(3) } \\ a_{1} & \text { fitting parameter of Eq.id=6\#(3) } \\ a_{2} & \text { fitting parameter of Eq.id=6\#(3) } \\ a_{3} & \text { fitting parameter of Eq.id=6\#(3) } \\ a_{4} & \text { fitting parameter of Eq.id=6\#(3) } \\ \text { bias } & \text { statistical bias } \\ l & \text { fitting parameter of Eq.id=6\#(4) }\left(\mathrm{m}^{3} \mathrm{~mol}^{-1}\right) \\ m & \text { fitting parameter of Eq.id=6\#(4) }\left(\mathrm{m}^{3} \mathrm{~mol}^{-1} \mathrm{~K}^{-1}\right) \\ M & \text { molecular mass }\left(\mathrm{kg} \mathrm{mol}{ }^{-1}\right) \\ n & \text { fitting parameter of Eq.id=6\#(4) }\left(\mathrm{m}^{3} \mathrm{~mol}^{-1} \mathrm{~K}^{-2}\right) \\ N & \text { number of data points } \\ N_{\mathrm{A}} & \text { Avogadro number } \\ p & \text { pressure }(\mathrm{MPa}) \\ R_{\mathrm{s}} & \text { wire radius }(\mathrm{m}) \\ R & \text { gas constant }\left(\mathrm{J} \mathrm{K} \mathrm{mol}^{-1}\right) \\ \mathrm{RMSD} & \text { root mean square deviation } \\ T & \text { temperature }(\mathrm{K}) \\ T_{\mathrm{b}} & \text { boiling temperature }(\mathrm{K}) \\ T_{\mathrm{c}} & \text { critical temperature }(\mathrm{K}) \\ T_{\mathrm{ref}} & \text { reference temperature }(\mathrm{K}) \\ U & \text { uncertainty } \\ V_{0} & \text { characteristic molar volume }\left(\mathrm{m}^{3} \mathrm{~mol}^{-1}\right) \\ V_{\mathrm{c}} & \text { critical molar volume }\left(\mathrm{m}^{3} \mathrm{~mol}^{-1}\right) \\ \mathrm{V}_{\mathrm{m}} & \text { molar volume }\left(\mathrm{m}^{3} \mathrm{~mol}{ }^{-1}\right) \\ X & \text { a generic property } \\ & \end{array}$

Greek letters

$\Delta_{0}$ dimensionless coefficient of internal damping

$\eta^{*} \quad$ dimensionless viscosity

$\eta \quad$ viscosity (mPas)

$\rho \quad$ fluid density $\left(\mathrm{kg} \mathrm{m}^{-3}\right)$

$\rho_{\mathrm{s}} \quad$ wire density $\left(\mathrm{kg} \mathrm{m}^{-3}\right)$

$\sigma_{\mathrm{HS}}$ hard-sphere diameter $(\mathrm{m})$

\section{Subscripts}

$i \quad i$ th datum

exp experimental

calc calculated

ref reference

\section{Introduction}

The knowledge of the viscosity of petroleum fluids at the oil reservoir temperatures and pressures seems at present to be a need of the oil exploration industries [1-7]. Moreover, several other industrial activities dealing with high viscosity fluids are also in need of reference materials for viscosity or of on-line high viscosity measurements. As a consequence, there is, at present, a demand for new industrial viscosity standards with various viscosities, at high pressures and high temperatures. Industrial viscosity standards with adequate viscosity could be used for calibration and tests of industrial viscometers for use in-well, or on-line, at the adequate working conditions [1-10]. Since, in industry the range of viscosity of useful fluids varies over several orders of magnitude, a number of "industrial reference materials", covering a large spectrum of practical conditions, are required to calibrate or verify the calibration of those instruments [8].

Often, in industry the calibration of viscometers is made directly or indirectly, using certified reference fluids, which have viscosities traceable to standards from national metrological laboratories, obtained with capillaries calibrated by a step-up procedure, from the water primary reference to the corresponding viscosity [8]. For very viscous liquids this procedure can be time consuming and expensive. Moreover, those certified reference fluids are usually mixtures of oils, whose composition has only a general description [8]. In face of this, the viscosity of these fluids must be determined for each batch and its utilization should take place within strictly defined time limits. These facts point to the convenience to establish secondary reference fluids for industrial use. Moreover, to the knowledge of the authors, there are no commercial certified reference fluids with certified viscosity data at pressures above atmospheric pressure.

As a consequence, the International Association for Transport Properties (IATP) has been developing efforts in order to respond to the demand of industrial viscosity standards [1-10]. In particular, IATP has proposed an industrial viscosity standard for moderately high viscosity [DIDP] and, more recently, has created an internal project regarding the search of a high viscosity industrial viscosity standard fluid, and at high pressures and high temperatures.

Also, in order to extend the range of viscosities, temperatures and pressures, presently available by viscosity reference fluids, IUPAC recently launched a project (No. 2012-051-1-100; 2013-0515 ), the main goal of which is to find a standard for viscosity with a nominal value of about $20 \mathrm{mPa} s( \pm 5 \%)$ at a temperature of $473 \mathrm{~K}$ and a pressure of $200 \mathrm{MPa}$ [11]. In our view, progress towards the establishment of industrial viscosity standards at the highest temperatures and pressures, presently being required, need several reference liquids, at intermediate values of those properties. The present work aims to contribute to the proposal of a relatively high viscosity reference fluid at moderately high pressures and temperatures.

Towards this goal, the former sub-committee on transport properties of IUPAC (STP-IUPAC), whose efforts have been continued by the International Association for Transport Properties (IATP), has contributed to the publication of new viscosity reference data for several pure liquids. In fact, in the last decades, viscosity reference data of low viscosity fluids [12-16] and moderately high viscosity fluids [6,8,9], have been proposed under the auspices of STP-IUPAC and IATP.

In particular toluene has been proposed $[14,15]$ to be a reference fluid for viscosity in wide ranges of temperature and pressure. Assael et al. [14] proposed a reference correlation for the viscosity of toluene in a range of temperatures from (213 to 373 ) $\mathrm{K}$ and pressures up to $250 \mathrm{MPa}$. Later, Assael et al. [17] proposed viscosity reference data for cyclopentane from (220 to 310 ) K up to $25 \mathrm{MPa}$. These proposals comprise viscosities ranging from $(0.2$ to 3$) \mathrm{mPa}$, which does not respond to the present demand for high viscosity reference liquids.

Studies carried out by Caetano et al. [18-20] have pointed out the potential qualities of diisodecyl phthalate (DIDP) to be an industrial viscosity reference liquid of moderately high viscosity. As a consequence, Caetano et al. [8] have recently proposed, under guidance of IATP, DIDP to be an industrial reference fluid for viscosity at $0.1 \mathrm{MPa}$, in the range of temperatures from (293 to $303) \mathrm{K}$, comprising a range of viscosities from (65.0 to 123.0) $\mathrm{mPa}$. Subsequently, high pressure viscosity and density measurements of DIDP were also published [21-27].

The fact that DIDP is commercialized as a mixture of isomers has led Caetano et al. [8] to perform studies about the influence of the purity of DIDP on its viscosity. In their studies they have shown that the viscosity of a sample $99 \%$ pure differs within $\pm 1.2 \%$ from the viscosity of a sample $99.8 \%$ pure. However, for two samples from different suppliers but with the same purity (99.8\% pure) the difference between their viscosities was within $\pm 0.3 \%$, showing those samples with eventually a different distribution of isomers, 
but with a similar overall purity, had essentially the same viscosity, well within the experimental uncertainty. Nevertheless, several authors $[5,6,9]$ have recently shown some doubts regarding the use of DIDP as a standard reference fluid. One important reason for this lies in the fact that the supplier of the high purity samples primarily used for the establishment of the DIDP reference data [8] is reported to have discontinued its production [9]. While an alternative liquid is not found, DIDP continues being used to verify the accuracy of some viscometers [26] and also for their calibration [9], and to the knowledge of the present authors, no other pure fluid has been proposed to be a reference fluid for such high viscosity; $123.0 \mathrm{mPa}$ s at $293 \mathrm{~K}$ and $0.1 \mathrm{MPa}$.

In the meantime several kinds of liquids, like phthalates $[7,21,27,28]$, sebacates [7,29], benzoates [21], squalane [6,9,21], perfluoropolyethers [5] and ionic liquids [30,31], have been suggested as possible candidates to be viscosity reference fluids at moderately high viscosity, as a replacement for DIDP.

$\mathrm{Di}$ (2-ethylhexyl) phthalate (DEHP) was pointed as a possible substitute of DIDP for moderately high viscosity standard [7,21]. However, DEHP was included by the European Chemical Agency in a list of possible high concern substances regarding their toxicity [32].

In order to fulfil the need of an industrial viscosity standard for moderately high viscosity, a reference correlation for viscosity of squalane, from (3.13 to 83.90 ) $\mathrm{mPa}$ s, at $0.1 \mathrm{MPa}$ and temperatures from ( 273 to 373 ) K was recently proposed by Comuñas et al. [6], and for pressures up to $200 \mathrm{MPa}$, from (0.85 to 954) $\mathrm{mPa}$ s and temperatures from (273 to 473) K proposed by Mylona et al. [10], being the first under the auspices of IATP and the second under the auspices of IUPAC (Project 2012-051-1-100). Recently, measurements of the viscosity of squalane have been published by Comuñas et al. [9] in a very wide range of pressures (up to $350 \mathrm{MPa}$ ), in a temperature range from (293 to 363) K. It should be noted that DIDP was used as a calibrant in some of those viscosity measurements of squalane reported in Ref. [9]. However those viscosity data were not used as primary data for the reference correlation of squalane reported in Ref. [10].

The possibility to use room temperature ionic liquids (RTILs) as reference fluids is very appealing because of the enormous ion combinations which can be used to select the appropriate characteristics for a viscosity standard. However, a number of difficulties, mainly related to the experimental handling of the liquids, and the experimental procedures of the measurement techniques, have shown to be very difficult to achieve very accurate and even reproduce viscosity results of ionic liquid samples [33], due to the significant effects on viscosity caused by contaminations, mainly halides or water. It has been shown that contaminations of the order of hundreds or tens of parts per million can cause important effects on viscosity [30,31,33,34].

Trimellitates have the adequate properties for being used as high viscosity reference liquids. Those compounds have a very low vapour pressure and have a very large temperature range in the liquid state; moreover, they have a reasonably low cost $[35,36]$. Trimellitates are adequate liquids for high temperature applications. Among of those applications are included two stroke and chain oils, greases and compressor fluids [37]. Tris(2-ethylhexyl) trimellitate or 1,2,4-Benzenetricarboxylic acid, tris(2-ethylhexyl) ester commonly known as TOTM, is about two times more viscous than DIDP and is one of the most used plasticizers in the polymer industry, which makes it available throughout the world $[35,36]$. It is used as plasticizer for flexible and high temperature resistant PVC products, and its utilization seems to be expanding [35-40]. To our knowledge, although TOTM is classified as harmful in contact with skin, and susceptible to cause serious eye irritation, it is not classified as dangerous, according to European Directive 67/548/ EEC [41].

The present paper reports new viscosity measurements of TOTM in a range of temperatures from (303 to 373) K and pressure up to $65 \mathrm{MPa}$. The density data required to compute the viscosity from the output of the vibrating-wire viscometer, were measured from (293 to 373) K up to $68 \mathrm{MPa}$, using an Anton Paar vibrating Utube densimeter, model DMA HP, which are described in part II [42] of the present work.

In our view, TOTM is a plausible candidate to contribute to the above mentioned goals, covering an extensive range of viscosities in a wide range of temperatures and pressures.

Moreover, TOTM is a liquid with high interest for the industry of polymers, therefore the present viscosity and density data can be useful either as reference data or directly in industrial processes involving that compound.

\section{Materials and methods}

\subsection{Materials}

The tris(2-ethylhexyl) trimellitate (CAS-No. 3319-31-1 and ECNo. 222-020-0) was acquired from Sigma-Aldrich with a nominal minimum purity of $99 \%$. Its purity was verified by ${ }^{1} \mathrm{H}$ and ${ }^{13} \mathrm{C}$ nuclear magnetic resonance spectrometry (NMR), and no contamination was detected. The samples were dried with molecular sieves from Sigma-Aldrich, with $0.4 \mathrm{~nm}$ porosity, and no further purification was performed. The Newtonian viscosity standard (NVS), traceable to the Physikalisch Technische Bundesanstalt (PTB), Germany, 20 AW, was acquired from Zentrum für Messen und Kalibrieren (ZMK)-Analytik-GmbH (Germany). This viscosity standard liquid was used for the calibration of the vibrating wire sensor, without any further treatment. Before introduction in the vibrating wire measurement cells, TOTM was filtered with an inline $15 \mu \mathrm{m}$ porosity sintered stainless steel filter. For the capillary viscosity measurements, a PTFE membrane filter with $0.2 \mu \mathrm{m}$ porosity was used. The sample was degassed and monitored for its water content, before and after all the viscosity measurements, using a Karl Fischer $831 \mathrm{KF}$ Coulometer from Metrohm. Table 1 summarizes the main characteristics of the sample and the standard oil NVS 20 AW.

\subsection{Vibrating wire method}

The vibrating wire viscometer was used in the forced mode which consists in obtaining the frequency response of the sensor

Table 1

Characterization of the liquids used in this work.

\begin{tabular}{|c|c|c|c|c|}
\hline Liquid & Lot number & Source of sample & Water content $\left(\mathrm{mg} \mathrm{kg}^{-1}\right)$ & Purity (Mass fraction) \\
\hline Tris(2-ethylhexyl) trimellitate (TOTM) & MKBH8084V & Sigma-Aldrich & $\mathrm{a}$ & $99 \%^{\mathrm{b}}$ \\
\hline NVS $20 \mathrm{AW}^{\mathrm{c}}$ & & ZMK-Analytik-GmbH & & NS \\
\hline
\end{tabular}

a The water content of the sample before and after the viscosity measurements are reported in Tables 3 and 6 .

b Mass fraction purity reported by the supplier.

c $\eta[(293.15,298.15$ and 313.15$) \mathrm{K}]=(19.55,16.02,9.497) \mathrm{mPa}$ s with $U= \pm 0.18 \%(k=2)$. All the values were reported by the supplier. NS - not specified. 


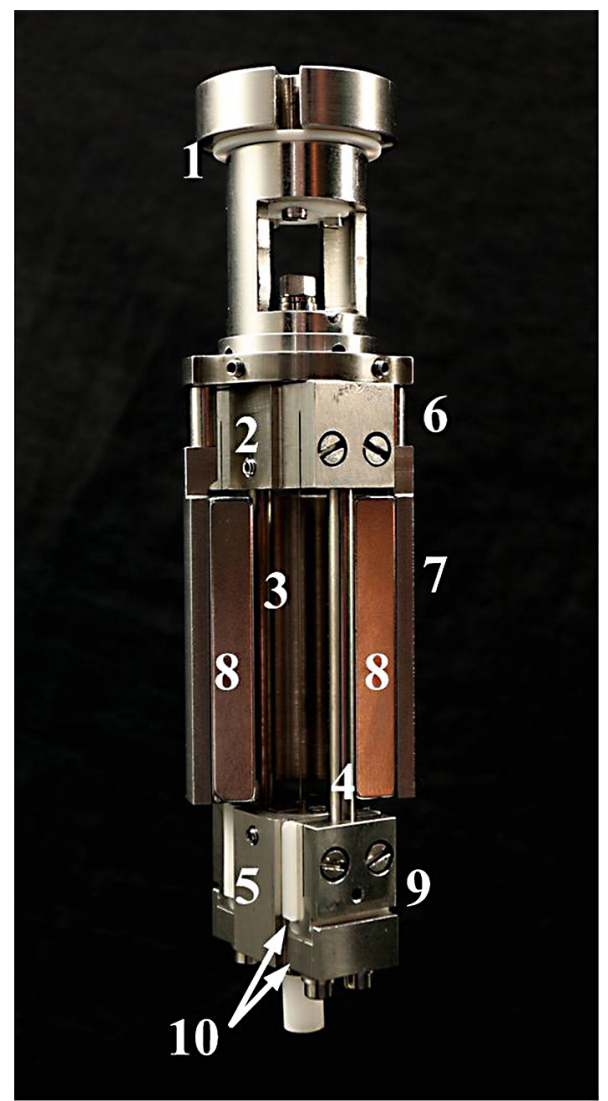

Fig. 1. New vibrating-wire sensor: 1 , top washers; 2 , upper claw chucks; 3 , vibrating wire; 4 , rod spacers; 5 , inferior claw chucks; 6 , superior rod clamping; 7 , magnetic circuit; 8 , magnets; 9 , inferior rod clamping, 10 , bottom washers.

around the resonance frequency [43]. The viscosity of the fluid can be determined from the complex voltage response of the sensor in the frequency domain, through the description of the hydrodynamic effects of the fluid on the oscillation parameters of the wire [43].The experimental procedure to determine the viscosity, in particular, the acquisition of the raw data and the electronic instrumentation used in the present work was previously described by Diogo et al. [45,46].

A lock-in amplifier (Perkin-Elmer, model 7225) was used both as a synthesizer of the variable-frequency driving current and as a multimeter to measure the voltage drop across the vibrating wire sensor, as described before $[18,19,45,46]$. A $100 \Omega$ resistor (grade $S$ standard resistor type 3504D from H. Tinsley \& Co. Ltd. U.K.) was connected in series with the sensor. A computer was used to control the instruments and to acquire the raw data through an Agilent 82357B GPIB/USB interface from Agilent Technologies.

\subsection{New vibrating wire sensor}

A new vibrating wire sensor for measuring viscosity at high pressures and at temperatures up to $373 \mathrm{~K}$ was designed, based on the vibrating wire sensor validated by Caetano et al. [47], which was used for accurate viscosity measurements up to $500 \mathrm{mPa}$, with molecular $[8,19,47]$ and ionic liquids $[33,45,46]$, after calibration with the viscosity primary reference, water at $293.15 \mathrm{~K}$ and $0.1 \mathrm{MPa}$. However, the later sensor was designed for atmospheric pressure measurements.

The new vibrating wire sensor (Fig. 1) has a tungsten wire (3 in Fig. 1) with $99.95 \%$ purity and a nominal diameter of $300 \mu \mathrm{m}$, supplied by Goodfellow (U.K.). All metallic components of the sensor (except the spacer rods) were made of stainless steel $316 \mathrm{~L}$.
The insulators at top of the sensor are made of PTFE at the bottom are made of Ertacetal ${ }^{\circledR}$ (1 and 10 in Fig. 1). In order to avoid tensions caused by temperature changes, two $5 \mathrm{~mm}$ diameter tungsten rods (4 in Fig. 1) (CoreWire, U.K.), are used as spacers. The tungsten wire is clamped at both ends with twoclaw chucks ( 2 and 5 in Fig. 1). The tungsten wire was tensioned, prior to clamping, using a weight with a mass of about $1.6 \mathrm{~kg}$, acquiring a resonance frequency of about $1 \mathrm{kHz}$ in air at room temperature corresponding to a vertical tension around $50 \%$ of the yield strength of tungsten [47-49].

The magnets (8 in Fig. 1) made of NdFeB (Magdev, U.K.), are $55 \mathrm{~mm}$ long and the magnetic circuit is made of stainless steel AISI 420 (7 in Fig. 1). One particular characteristic of the magnetic circuit assembly is that it can be replaced without changing the tension of the wire, which may be useful if magnets with a higher Curie temperature must be placed in order to enable work at higher temperatures. The distance of the magnets and the spacers to the tungsten wire was set at a minimum of 60 times the wire radius, $R_{\mathrm{s}}$, which is deemed to introduce an error less than $0.2 \%$ due to the finite distance from the cell walls $[44,47-50]$.

\subsubsection{Vibrating wire viscometer parameters}

The parameters of the sensor are shown in Table 2. The wire radius has been determined by calibration with the Newtonian viscosity standard $20 \mathrm{AW}$ [51] from ZMK-Analytik-GmbH, at $298.15 \mathrm{~K}$ and $0.1 \mathrm{MPa}$, having a tabulated viscosity of $16.02 \mathrm{mPa} \mathrm{s}$ [51]. The expanded uncertainty reported by the corresponding calibration certificate [51] is $\pm 0.18 \%$, at a confidence level of $95 \%$ $(k=2)$. The wire density was taken from the literature [52] and the internal damping was determined from the frequency response of the sensor under vacuum as described in Ref. [48].

\subsubsection{Vibrating wire viscometer setup}

The vibrating wire sensor was mounted in a stainless steel high pressure vessel supplied by Newport Scientific, Inc. (USA), rated to a pressure of about $120 \mathrm{MPa}$ (14 in Fig. 2). The pressure line (Fig. 2) is divided in two sections. One section is filled with a hydraulic fluid and includes three pressure transducers, model 206 (Setra Systems Inc. USA) set to the maximum working pressures of $(7,35$, and 70) MPa with uncertainties of $( \pm 0.01, \pm 0.05, \pm 0.09) \mathrm{MPa}$, respectively (10, 6 and 9 in Fig. 2). The other section was filled with the TOTM sample and includes the high pressure vessel (14 in Fig. 2) with the vibrating wire sensor and a pressure transducer (Setra model 206 with a maximum working pressure of $35 \mathrm{MPa}$, $\pm 0.05 \mathrm{MPa}$ ). The two sections are separated by a moving piston, placed within a high pressure tubular micro reactor model MS19 rated to $140 \mathrm{MPa}$ (High Pressure Equipment Company, USA, 13 in Fig. 2). The pressure needed to move the piston is lower than $0.01 \mathrm{MPa}$. Pressure can be applied in both sections (both sides of the moving piston) through two pressure generators model 50-615 (2 in Fig. 2), from High Pressure Equipment Company (USA),

Table 2

Parameters of the vibrating wire sensor at $T_{\text {ref. }}$

\begin{tabular}{llll}
\hline & $T_{\text {ref }}(\mathrm{K})$ & & \\
\hline Tungsten wire & & & \\
$\quad$ Radius $^{\mathrm{a}}$ & 298.15 & $R_{\mathrm{s}}(\mathrm{m})$ & $151.51 \times 10^{-6}$ \\
Density $^{\mathrm{b}}$ [52] & 293.15 & $\rho_{\mathrm{s}}\left(\mathrm{kg} \mathrm{m}^{-3}\right)$ & 19230 \\
Resonance under vacuum & & & \\
$\quad \begin{array}{l}\text { Frequency } \\
\text { Internal damping coefficient }\end{array}$ & 297 & $\omega_{1}\left(\mathrm{rad} \mathrm{s}^{-1}\right)$ & 6358 \\
& 297 & $\Delta_{0}$ & $1.1 \times 10^{-4}$ \\
\hline
\end{tabular}

The viscosity of the NVS $20 \mathrm{AW}$, used in the viscometer calibration, at $298.15 \mathrm{~K}$ is $16.02 \mathrm{mPa}$.

a By calibration.

b From the literature.

c Measured. 
with a maximum working pressure of about $100 \mathrm{MPa}$. The sample section is provided with a $15 \mu \mathrm{m}$ porosity filter near the entrance of the sample of TOTM (15 in Fig. 2).

A Lauda UB 65 J thermostatic bath, filled with silicone oil, was used, with a Lauda R $400 \mathrm{P}$ temperature controller to maintain the temperature stable during each measurement run within $\pm 0.005 \mathrm{~K}$. For temperatures below $343 \mathrm{~K}$ a circulating cryostat Haake Phoenix C41P (Thermo Electron Corporation) was used as an external cooling source. The temperature was measured using a $100 \Omega$ platinum resistance thermometer, mounted close to the outside surface of the pressure vessel, calibrated by EIA, Portugal, using a multimeter (Prema, model 6001) as a reading unit, with an overall estimated uncertainty of $\pm 0.05 \mathrm{~K}$.

The expanded uncertainty of the present vibrating-wire measurements, at a 95\% confidence level, is estimated to be less than $\pm 2 \%$, for viscosities up to $68 \mathrm{mPas}$, less than $\pm 2.6 \%$ for viscosities between (69 and 268) $\mathrm{mPas}$ and less than $\pm 3 \%$ for higher viscosities. These estimates were partly based on previous sensitivity studies $[19,20,45,46]$. The repeatability of the measurements, at the same confidence level, is better than $\pm 0.2 \%$ for the lowest viscosity, increasing to a maximum of $\pm 0.4 \%$ for the highest viscosity.

\subsection{Capillary viscosity measurements}

Independent measurements of the viscosity of tris(2-ethylhexyl) trimellitate at atmospheric pressure were performed using an automatic Schott ViscoSystem ${ }^{\mathbb{R}}$ AVS 440 measuring unit fitted with an Ubbelohde viscometer of type $54123 /$ IIc, manufactured by Schott Instruments $\mathrm{GmbH}$. The Ubbelohde capillary has been calibrated with the viscosity standard specimen 100B, from PTB, Germany, as described in Ref. [8]. The experimental setup and procedure were previously described by Diogo et al. [33]. The temperature of the thermostatic oil was measured, with a $100 \Omega$ platinum resistance thermometer, calibrated by EIA (Portugal) with an overall estimated uncertainty of $\pm 0.05 \mathrm{~K}$. The capillary was immersed in a silicone oil thermostatic bath (Schott-Geräte CT1445). A Thermo NESLAB RTE7 cryostat was used as a cooling source. The temperature was stable within $\pm 0.01 \mathrm{~K}$ during a series of measurements. Based on previous sensitivity studies $[9,33,45]$, the overall maximum uncertainty of these viscosity measurements was estimated as $\pm 1.5 \%$.

\subsection{Vibrating $U$-tube density measurements}

The complementary density results necessary to obtain the vibrating wire and capillary viscosity raw data were measured from (293 to 373) $\mathrm{K}$ up to $68 \mathrm{MPa}$, along five isotherms, using a DMA HP vibrating U-tube densimeter from Anton Paar, according to the procedure and calibration equation described by Brito e Abreu et al. [24]. Those density measurements are presented in part II of this work [42]. The estimated overall maximum measurement uncertainty is $\pm 0.2 \%[24,53]$.

\section{Results and comparisons}

\subsection{Viscosity measurements of TOTM using the vibrating wire technique}

The viscosity of tris(2-ethylhexyl) trimellitate was measured with a vibrating-wire viscometer at pressures from (1 to 65) MPa, along six isotherms between (303 and 373 ) $\mathrm{K}$. The results are shown in Table 3. The density data, shown in Table 3, needed to compute the vibrating wire viscosity data were obtained using Eq. (6) with parameters of Table 4 from part II [42] of the present work. These density data used were corrected for the effect of viscosity on the U-tube density measurements. The correction procedure is described in part II of this work [42]. As the density and viscosity are mutually influenced by that correction, the data shown in Table 3 for both properties have been corrected using an iterative procedure. However, the number of iterations is very small, because of the order of magnitude of the corrections and to the low sensitivity of the viscosity obtained by the vibrating-wire method to the density. In fact, a correction in the density of about $0.1 \%$ leads to a variation smaller than $0.05 \%$ in the viscosity obtained with the present vibrating wire technique. The density data with and without correction for the viscosity effect on the Utube density measurements are presented in Table 3 of part II [42].

\subsubsection{Correlation of the viscosity with density using a hard-spheres scheme}

The viscosity data of TOTM were correlated with density using a semi-empirical method proposed by Li et al. [54] which is a heuristic development of the kinetic theory for dense hard-sphere fluids, applied to the van der Waals model of a liquid [55].

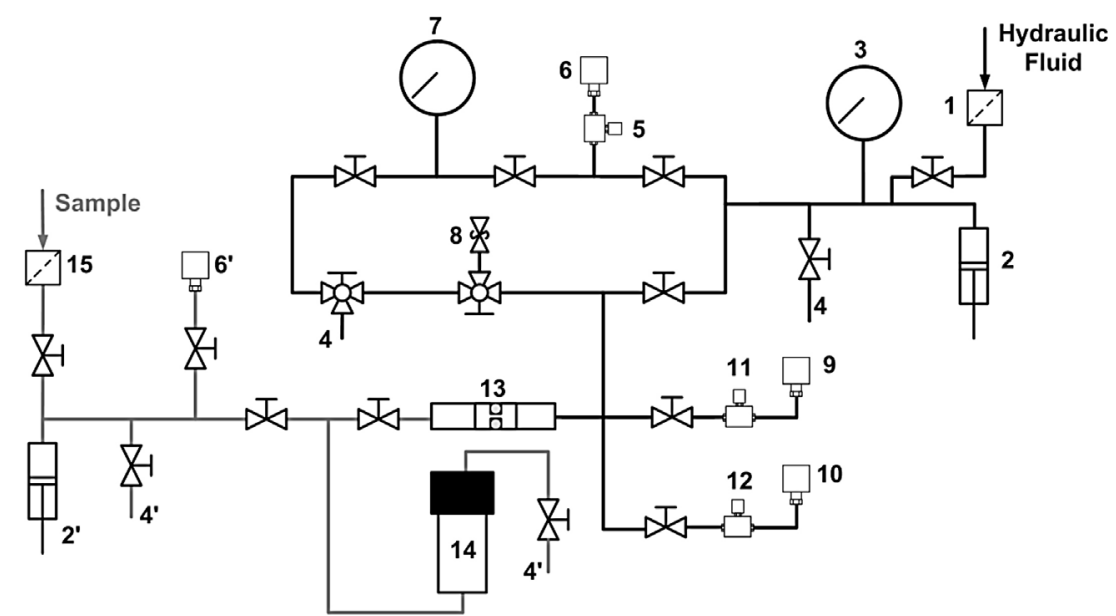

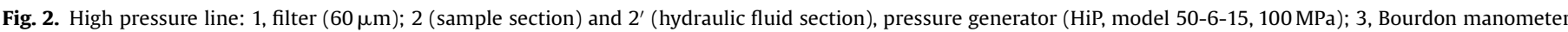

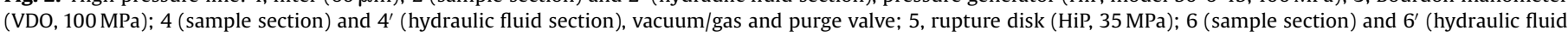

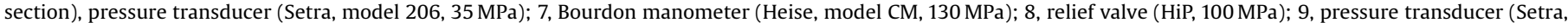

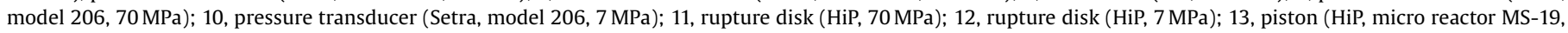
$140 \mathrm{MPa}) ; 14$, high pressure vessel (Newport Scientific, $120 \mathrm{MPa}) ; 15$, filter $(15 \mu \mathrm{m})$. 
Table 3

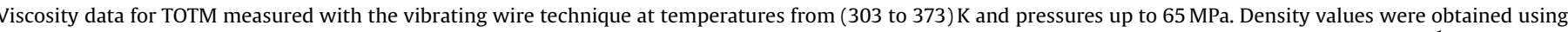

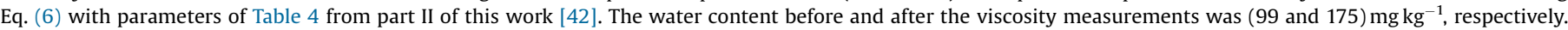

\begin{tabular}{|c|c|c|c|c|c|c|c|c|c|c|c|c|c|c|c|}
\hline$T(\mathrm{~K})$ & $p(\mathrm{MPa})$ & $\rho\left(\mathrm{kg} \mathrm{m}^{-3}\right)$ & $\eta(\mathrm{mPa} s)$ & $T(\mathrm{~K})$ & $p(\mathrm{MPa})$ & $\rho\left(\mathrm{kg} \mathrm{m}^{-3}\right)$ & $\eta(\mathrm{mPa} s)$ & $T(\mathrm{~K})$ & $p(\mathrm{MPa})$ & $\rho\left(\mathrm{kg} \mathrm{m}^{-3}\right)$ & $\eta(\mathrm{mPas})$ & $T(\mathrm{~K})$ & $p(\mathrm{MPa})$ & $\rho\left(\mathrm{kg} \mathrm{m}^{-3}\right)$ & $\eta(\mathrm{mPa} s)$ \\
\hline 303.15 & 1.08 & 981.4 & 158.9 & 313.17 & 29.94 & 990.7 & 159.5 & 328.16 & 40.59 & 986.6 & 89.1 & 358.18 & 2.5 & 942.6 & 14.16 \\
\hline 303.15 & 1.03 & 981.3 & 158.4 & 313.16 & 29.98 & 990.8 & 159.8 & 328.15 & 40.61 & 986.6 & 89.47 & 358.18 & 2.49 & 942.6 & 14.11 \\
\hline 303.15 & 0.98 & 981.3 & 158.5 & 313.16 & 29.97 & 990.7 & 160.2 & 328.16 & 40.62 & 986.6 & 89.25 & 358.18 & 2.48 & 942.6 & 14.11 \\
\hline 303.16 & 2.82 & 982.4 & 165 & 313.16 & 29.93 & 990.7 & 159.8 & & & & & 358.18 & 2.47 & 942.6 & 14.13 \\
\hline 303.16 & 2.85 & 982.4 & 165.1 & 313.17 & 29.94 & 990.7 & 159.5 & & & & & 358.18 & 4.92 & 944.4 & 14.69 \\
\hline 303.16 & 2.85 & 982.4 & 165.7 & 313.16 & 29.98 & 990.8 & 159.8 & 343.15 & 1.04 & 952.2 & 22.81 & 358.18 & 4.86 & 944.4 & 14.68 \\
\hline 303.16 & 5.13 & 983.8 & 173.8 & 313.16 & 39.98 & 996 & 197 & 343.15 & 1.05 & 952.2 & 22.74 & 358.18 & 4.96 & 944.4 & 14.64 \\
\hline 303.16 & 5.13 & 983.8 & 173.6 & 313.16 & 40.02 & 996 & 196.6 & 343.15 & 1.09 & 952.3 & 22.81 & 358.18 & 4.84 & 944.3 & 14.65 \\
\hline 303.16 & 5.13 & 983.8 & 173.8 & 313.16 & 40 & 996 & 196.9 & 343.15 & 1.06 & 952.3 & 22.78 & 358.18 & 4.99 & 944.5 & 14.64 \\
\hline 303.16 & 5.12 & 983.8 & 174.3 & 313.16 & 39.96 & 995.9 & 197.4 & 343.15 & 1.07 & 952.3 & 22.74 & 358.18 & 7.42 & 946.2 & 15.37 \\
\hline 303.16 & 5.13 & 983.8 & 173.4 & 313.16 & 50.09 & 1000.9 & 239.3 & 343.14 & 1.08 & 952.3 & 22.75 & 358.18 & 7.42 & 946.2 & 15.38 \\
\hline 303.16 & 7.68 & 985.3 & 183.3 & 313.16 & 50.08 & 1000.9 & 239.6 & 343.15 & 2.54 & 953.3 & 23.48 & 358.18 & 7.41 & 946.2 & 15.34 \\
\hline 303.16 & 7.68 & 985.3 & 183.9 & 313.16 & 50.07 & 1000.9 & 239.5 & 343.15 & 2.58 & 953.3 & 23.42 & 358.18 & 7.36 & 946.2 & 15.35 \\
\hline 303.16 & 7.69 & 985.3 & 183.8 & 313.16 & 50.04 & 1000.9 & 240.3 & 343.15 & 2.54 & 953.3 & 23.48 & 358.18 & 7.37 & 946.2 & 15.37 \\
\hline 303.16 & 7.68 & 985.3 & 183.8 & 313.16 & 50.04 & 1000.9 & 239.4 & 343.15 & 2.54 & 953.3 & 23.4 & 358.18 & 7.39 & 946.2 & 15.35 \\
\hline 303.16 & 7.68 & 985.3 & 183.6 & 313.16 & 50.02 & 1000.9 & 239.1 & 343.15 & 4.8 & 954.9 & 24.49 & 358.18 & 10.35 & 948.3 & 16.11 \\
\hline 303.16 & 9.88 & 986.5 & 194.1 & 313.16 & 65.47 & 1008.1 & 317.5 & 343.15 & 4.9 & 955 & 24.44 & 358.18 & 10.38 & 948.4 & 16.12 \\
\hline 303.16 & 9.85 & 986.5 & 193.9 & 313.16 & 65.44 & 1008.1 & 319.8 & 343.15 & 4.9 & 955 & 24.52 & 358.18 & 10.41 & 948.4 & 16.11 \\
\hline 303.16 & 9.83 & 986.5 & 193.9 & 313.16 & 65.47 & 1008.1 & 317.5 & 343.15 & 4.9 & 955 & 24.43 & 358.19 & 10.47 & 948.4 & 16.13 \\
\hline 303.15 & 15.06 & 989.5 & 220.6 & 313.16 & 65.43 & 1008.1 & 319 & 343.15 & 4.88 & 955 & 24.44 & 358.18 & 15.32 & 951.8 & 17.52 \\
\hline 303.15 & 15.06 & 989.5 & 220.2 & 313.16 & 65.42 & 1008.1 & 317.8 & 343.15 & 4.82 & 954.9 & 24.51 & 358.19 & 15.34 & 951.8 & 17.51 \\
\hline 303.16 & 20.01 & 992.2 & 243.8 & & & & & 343.15 & 7.53 & 956.8 & 25.82 & 358.19 & 15.36 & 951.9 & 17.51 \\
\hline 303.16 & 19.99 & 992.2 & 242.8 & & & & & 343.15 & 7.59 & 956.8 & 25.76 & 358.19 & 15.37 & 951.9 & 17.52 \\
\hline 303.16 & 19.98 & 992.2 & 242.8 & 328.16 & 1 & 963 & 41.66 & 343.15 & 7.63 & 956.9 & 25.78 & 358.19 & 15.39 & 951.9 & 17.53 \\
\hline 303.16 & 19.95 & 992.2 & 242.6 & 328.16 & 1.03 & 963.1 & 41.61 & 343.15 & 7.65 & 956.9 & 25.77 & 358.19 & 15.41 & 951.9 & 17.54 \\
\hline 303.15 & 29.82 & 997.4 & 303.1 & 328.16 & 1.03 & 963.1 & 41.82 & 343.14 & 10.14 & 958.6 & 27.1 & 358.18 & 20.13 & 955.1 & 19.05 \\
\hline 303.15 & 29.81 & 997.4 & 302.4 & 328.16 & 1.05 & 963.1 & 41.76 & 343.15 & 10.14 & 958.6 & 27.08 & 358.18 & 20.12 & 955.1 & 18.99 \\
\hline 303.16 & 29.82 & 997.4 & 303.5 & 328.15 & 2.52 & 964.1 & 43.29 & 343.14 & 10.15 & 958.6 & 27.11 & 358.18 & 20.07 & 955 & 19.03 \\
\hline 303.15 & 29.81 & 997.4 & 302.1 & 328.16 & 2.52 & 964.1 & 43.23 & 343.14 & 10.15 & 958.6 & 27.07 & 358.18 & 20.09 & 955.1 & 18.99 \\
\hline 303.16 & 29.82 & 997.4 & 303.8 & 328.15 & 2.49 & 964 & 43.18 & 343.14 & 10.15 & 958.6 & 27.11 & 358.18 & 20.05 & 955 & 18.99 \\
\hline 303.16 & 29.83 & 997.4 & 302.3 & 328.16 & 2.53 & 964.1 & 43.31 & 343.15 & 15.09 & 961.8 & 29.74 & 358.18 & 20.07 & 955 & 18.97 \\
\hline 303.16 & 40.17 & 1002.6 & 370.5 & 328.16 & 2.51 & 964.1 & 43.2 & 343.15 & 15.07 & 961.8 & 29.73 & 358.19 & 30.31 & 961.6 & 22.42 \\
\hline 303.16 & 40.17 & 1002.6 & 373.1 & 328.16 & 5.13 & 965.8 & 45.73 & 343.15 & 15.06 & 961.8 & 29.74 & 358.19 & 30.38 & 961.7 & 22.43 \\
\hline 303.16 & 40.18 & 1002.6 & 373.2 & 328.16 & 5.1 & 965.8 & 45.73 & 343.15 & 15.05 & 961.8 & 29.64 & 358.19 & 30.36 & 961.7 & 22.4 \\
\hline 303.16 & 40.18 & 1002.6 & 369.5 & 328.16 & 5.14 & 965.8 & 45.67 & 343.15 & 15.04 & 961.8 & 29.65 & 358.19 & 30.38 & 961.7 & 22.47 \\
\hline 303.16 & 40.16 & 1002.6 & 369.8 & 328.15 & 5.12 & 965.8 & 45.81 & 343.15 & 15.04 & 961.8 & 29.63 & 358.19 & 30.38 & 961.7 & 22.46 \\
\hline 303.16 & 40.17 & 1002.6 & 370.9 & 328.16 & 5.1 & 965.8 & 45.69 & 343.14 & 19.93 & 964.9 & 32.41 & 358.18 & 40.29 & 967.6 & 26.24 \\
\hline 303.17 & 50.4 & 1007.5 & 463.8 & 328.16 & 5.13 & 965.8 & 45.72 & 343.14 & 19.92 & 964.9 & 32.38 & 358.18 & 40.28 & 967.6 & 26.21 \\
\hline 303.17 & 50.4 & 1007.5 & 462 & 328.15 & 7.54 & 967.3 & 47.59 & 343.14 & 19.91 & 964.9 & 32.45 & 358.18 & 40.26 & 967.6 & 26.24 \\
\hline 303.17 & 50.4 & 1007.5 & 460 & 328.15 & 7.55 & 967.4 & 47.68 & 343.14 & 19.9 & 964.9 & 32.35 & 358.18 & 40.25 & 967.6 & 26.27 \\
\hline 303.17 & 50.39 & 1007.5 & 462.2 & 328.15 & 7.56 & 967.4 & 47.66 & 343.14 & 19.89 & 964.9 & 32.41 & 358.18 & 40.24 & 967.6 & 26.25 \\
\hline \multirow[t]{3}{*}{303.17} & 50.4 & 1007.5 & 462.1 & 328.16 & 7.58 & 967.4 & 47.76 & 343.14 & 19.9 & 964.9 & 32.43 & 358.19 & 50.36 & 973.4 & 30.62 \\
\hline & & & & 328.15 & 10.43 & 969.2 & 50.81 & 343.14 & 30.25 & 971.2 & 38.67 & 358.19 & 50.42 & 973.4 & 30.65 \\
\hline & & & & 328.15 & 10.41 & 969.2 & 50.91 & 343.14 & 30.26 & 971.2 & 38.59 & 358.19 & 50.38 & 973.4 & 30.63 \\
\hline 313.16 & 1.23 & 974.1 & 87.98 & 328.16 & 10.41 & 969.2 & 50.74 & 343.14 & 30.25 & 971.2 & 38.63 & 358.19 & 50.39 & 973.4 & 30.61 \\
\hline 313.16 & 1.22 & 974.1 & 87.78 & 328.16 & 10.4 & 969.2 & 50.84 & 343.14 & 30.24 & 971.2 & 38.59 & 358.19 & 50.4 & 973.4 & 30.65 \\
\hline 313.16 & 1.32 & 974.2 & 87.62 & 328.16 & 10.39 & 969.2 & 50.78 & 343.14 & 30.25 & 971.2 & 38.6 & 358.19 & 65.54 & 981.4 & 38.26 \\
\hline 313.16 & 1.31 & 974.2 & 88.02 & 328.16 & 10.4 & 969.2 & 50.82 & 343.14 & 40.28 & 977 & 45.91 & 358.19 & 65.55 & 981.4 & 38.23 \\
\hline 313.16 & 1.32 & 974.2 & 87.55 & 328.15 & 15.14 & 972.1 & 55.66 & 343.14 & 40.27 & 977 & 45.89 & 358.19 & 65.57 & 981.4 & 38.28 \\
\hline 313.17 & 2.78 & 975.1 & 90.59 & 328.16 & 15.13 & 972.1 & 55.62 & 343.14 & 40.27 & 977 & 45.83 & 358.19 & 65.6 & 981.5 & 38.23 \\
\hline 313.17 & 2.8 & 975.1 & 90.3 & 328.16 & 15.11 & 972.1 & 55.52 & 343.14 & 40.26 & 977 & 45.94 & 358.19 & 65.61 & 981.5 & 38.23 \\
\hline 313.17 & 2.79 & 975.1 & 90.29 & 328.16 & 15.1 & 972.1 & 55.71 & 343.14 & 40.26 & 977 & 45.94 & & & & \\
\hline 313.17 & 2.78 & 975.1 & 90.6 & 328.16 & 15.1 & 972.1 & 55.71 & 343.14 & 49.87 & 982.2 & 53.82 & & & & \\
\hline 313.17 & 2.79 & 975.1 & 90.54 & 328.15 & 20.02 & 975.1 & 60.75 & 343.14 & 49.87 & 982.2 & 53.79 & 373.17 & 1.08 & 930.9 & 8.99 \\
\hline 313.16 & 2.78 & 975.1 & 90.52 & 328.15 & 20.04 & 975.1 & 60.75 & 343.14 & 49.84 & 982.2 & 53.72 & 373.17 & 1.07 & 930.9 & 8.988 \\
\hline 313.16 & 5.19 & 976.6 & 96.26 & 328.15 & 20.04 & 975.1 & 60.87 & 343.14 & 49.86 & 982.2 & 53.79 & 373.17 & 1.07 & 930.9 & 8.981 \\
\hline 313.16 & 5.21 & 976.6 & 95.79 & 328.16 & 20.02 & 975.1 & 60.83 & 343.14 & 49.84 & 982.2 & 53.82 & 373.17 & 1.07 & 930.9 & 8.984 \\
\hline 313.16 & 5.17 & 976.6 & 96.24 & 328.16 & 20.03 & 975.1 & 60.93 & 343.14 & 65.1 & 990 & 68.38 & 373.17 & 1.07 & 930.9 & 8.981 \\
\hline 313.17 & 5.17 & 976.6 & 95.9 & 328.16 & 30.42 & 981.1 & 74.4 & 343.14 & 65.08 & 989.9 & 68.37 & 373.18 & 2.5 & 932 & 9.245 \\
\hline 313.16 & 5.16 & 976.6 & 96.14 & 328.15 & 30.41 & 981.1 & 74.65 & 343.14 & 65.07 & 989.9 & 68.22 & 373.18 & 2.47 & 932 & 9.234 \\
\hline 313.16 & 7.79 & 978.2 & 101.3 & 328.15 & 30.4 & 981.1 & 74.44 & 343.14 & 65.06 & 989.9 & 68.25 & 373.18 & 2.46 & 932 & 9.209 \\
\hline 313.16 & 7.71 & 978.1 & 101.6 & 328.15 & 30.42 & 981.1 & 74.52 & 343.14 & 65.05 & 989.9 & 68.46 & 373.18 & 2.47 & 932 & 9.234 \\
\hline 313.16 & 7.78 & 978.2 & 101.7 & 328.15 & 50.08 & 991.5 & 105.8 & 343.14 & 50.34 & 982.4 & 53.74 & 373.18 & 2.46 & 932 & 9.224 \\
\hline 313.16 & 7.78 & 978.2 & 101.9 & 328.15 & 50.07 & 991.5 & 105.9 & 343.14 & 50.36 & 982.5 & 53.81 & 373.18 & 2.46 & 932 & 9.213 \\
\hline 313.16 & 7.78 & 978.2 & 101.4 & 328.15 & 50.05 & 991.5 & 105.7 & 343.14 & 50.36 & 982.5 & 53.95 & 373.17 & 2.69 & 932.2 & 9.227 \\
\hline 313.16 & 14.82 & 982.3 & 117.4 & 328.15 & 50.04 & 991.5 & 105.5 & 343.14 & 50.36 & 982.5 & 53.91 & 373.18 & 2.71 & 932.2 & 9.252 \\
\hline 313.16 & 14.8 & 982.3 & 117.6 & 328.15 & 50.04 & 991.5 & 105.7 & 343.14 & 50.35 & 982.5 & 53.88 & 373.17 & 2.72 & 932.2 & 9.242 \\
\hline 313.17 & 14.77 & 982.3 & 117 & 328.16 & 50.04 & 991.5 & 105.5 & & & & & 373.17 & 2.73 & 932.2 & 9.241 \\
\hline 313.17 & 20.06 & 985.3 & 132 & 328.15 & 50.03 & 991.5 & 105.8 & & & & & 373.17 & 5.14 & 934.1 & 9.653 \\
\hline 313.16 & 20.04 & 985.3 & 132.4 & 328.15 & 50.03 & 991.5 & 105.5 & 358.19 & 1.29 & 941.7 & 13.79 & 373.17 & 5.13 & 934.1 & 9.669 \\
\hline 313.16 & 20.06 & 985.3 & 131.6 & 328.15 & 50.03 & 991.5 & 105.9 & 358.19 & 1.33 & 941.7 & 13.79 & 373.17 & 5.12 & 934.1 & 9.651 \\
\hline 313.16 & 20.05 & 985.3 & 131.6 & 328.16 & 65.49 & 999 & 139.6 & 358.19 & 1.38 & 941.7 & 13.85 & 373.17 & 5.11 & 934.1 & 9.649 \\
\hline 313.16 & 29.97 & 990.7 & 160.2 & 328.15 & 65.53 & 999.1 & 139.6 & 358.18 & 2.53 & 942.6 & 14.14 & 373.17 & 5.11 & 934.1 & 9.654 \\
\hline 313.16 & 29.93 & 990.7 & 159.8 & 328.16 & 40.57 & 986.6 & 89.15 & 358.18 & 2.46 & 942.6 & 14.15 & 373.17 & 5.1 & 934.1 & 9.651 \\
\hline 373.17 & 7.5 & 936 & 10.03 & 373.18 & 20.29 & 945.4 & 12.3 & 373.18 & 50.28 & 964.4 & 19.18 & & & & \\
\hline
\end{tabular}


Table 3 (Continued)

\begin{tabular}{|c|c|c|c|c|c|c|c|c|c|c|c|c|c|c|c|}
\hline$T(\mathrm{~K})$ & $p(\mathrm{MPa})$ & $\rho\left(\mathrm{kg} \mathrm{m}^{-3}\right)$ & $\eta(\mathrm{mPa} s)$ & $T(\mathrm{~K})$ & $p(\mathrm{MPa})$ & $\rho\left(\mathrm{kg} \mathrm{m}^{-3}\right)$ & $\eta(\mathrm{mPa} s)$ & $T(\mathrm{~K})$ & $p(\mathrm{MPa})$ & $\rho\left(\mathrm{kg} \mathrm{m}^{-3}\right)$ & $\eta(\mathrm{mPa} s)$ & $T(\mathrm{~K})$ & $p(\mathrm{MPa})$ & $\rho\left(\mathrm{kg} \mathrm{m}^{-3}\right)$ & $\eta(\mathrm{mPa} s)$ \\
\hline 373.17 & 7.48 & 936 & 10.03 & 373.18 & 20.25 & 945.4 & 12.27 & 373.18 & 50.31 & 964.4 & 19.17 & & & & \\
\hline 373.17 & 7.48 & 935.9 & 10.03 & 373.18 & 20.27 & 945.4 & 12.29 & 373.18 & 50.29 & 964.4 & 19.21 & & & & \\
\hline 373.17 & 7.47 & 935.9 & 10.05 & 373.18 & 20.26 & 945.4 & 12.27 & 373.18 & 50.29 & 964.4 & 19.23 & & & & \\
\hline 373.17 & 7.44 & 935.9 & 10.06 & 373.18 & 20.25 & 945.4 & 12.26 & 373.18 & 65.37 & 972.8 & 23.68 & & & & \\
\hline 373.17 & 10.45 & 938.2 & 10.57 & 373.18 & 30.03 & 952 & 14.28 & 373.18 & 65.35 & 972.8 & 23.72 & & & & \\
\hline 373.18 & 10.46 & 938.2 & 10.56 & 373.18 & 30.03 & 952 & 14.28 & 373.18 & 65.33 & 972.8 & 23.7 & & & & \\
\hline 373.17 & 10.43 & 938.2 & 10.53 & 373.18 & 29.98 & 951.9 & 14.31 & 373.17 & 65.29 & 972.7 & 23.71 & & & & \\
\hline 373.18 & 10.44 & 938.2 & 10.57 & 373.18 & 30.01 & 952 & 14.3 & & & & & & & & \\
\hline 373.18 & 10.45 & 938.2 & 10.52 & 373.18 & 30 & 952 & 14.27 & & & & & & & & \\
\hline 373.17 & 15.16 & 941.7 & 11.29 & 373.18 & 29.99 & 952 & 14.32 & & & & & & & & \\
\hline 373.17 & 15.18 & 941.7 & 11.28 & 373.18 & 40.19 & 958.4 & 16.64 & & & & & & & & \\
\hline 373.17 & 15.21 & 941.8 & 11.32 & 373.18 & 40.17 & 958.4 & 16.61 & & & & & & & & \\
\hline 373.17 & 15.21 & 941.8 & 11.32 & 373.18 & 40.14 & 958.4 & 16.57 & & & & & & & & \\
\hline 373.17 & 15.21 & 941.8 & 11.33 & 373.18 & 40.15 & 958.4 & 16.63 & & & & & & & & \\
\hline 373.17 & 15.21 & 941.8 & 11.27 & 373.18 & 40.13 & 958.4 & 16.58 & & & & & & & & \\
\hline 373.18 & 20.32 & 945.4 & 12.28 & 373.18 & 50.32 & 964.4 & 19.23 & & & & & & & & \\
\hline
\end{tabular}

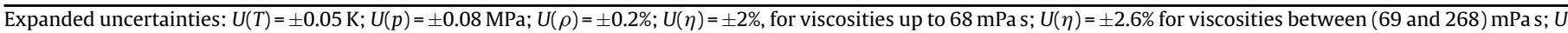
$(\eta) \pm 3 \%$ for higher viscosities.

This correlation scheme was used previously to correlate viscosity data for dimethyl adipate [53], 2,2,4-trimethylpentane [56], HFC134a [57], toluene [58], HFC-143a and HFC-125 [59], R507 A [60], and for constructing a reference correlation for the viscosity of toluene [14] in wide ranges of temperature and pressure.

Since we are seeking the best correlation for just one substance, it is preferred to use a taylor-made equation calculated exclusively for TOTM, rather than use a "universal" expression, like that proposed by Assael et al. [61]. This has also been the choice made by Assael et al. [14] to obtain the reference correlation proposed for viscosity of toluene at high pressures.

The correlation method used defines a dimensionless viscosity, $\eta^{*}$, that, using SI units, is written as [54]

$\eta *=6.035 \times 10^{8}\left(\frac{1}{M R T}\right)^{1 / 2} \eta\left(V_{\mathrm{m}}\right)^{2 / 3}$

where $M$ is the molar mass, $R$ is the gas constant, $T$ is the temperature and $V_{\mathrm{m}}$ is the molar volume. In this scheme, it is assumed that the dimensionless viscosity, $\eta^{*}$, depends only on $V_{\mathrm{m}} /$ $V_{0}$, where $V_{0}$ is a characteristic molar volume:

$\eta *=f_{\eta}\left(\frac{V_{\mathrm{m}}}{V_{0}}\right)$

Therefore, it is possible to obtain a single curve of $\eta^{*}$ as a function of $\ln \left(V_{\mathrm{m}} / V_{0}\right)$, by performing horizontal shifts along the $\ln$ $\left(V_{\mathrm{m}} / V_{0}\right)$ axis, thus obtaining the value of $V_{0}$ for each temperature. This slight temperature dependence of $V_{0}$ is interpreted as providing the ability to correct for the finite gradient of the repulsive potential of real molecules [54].The dimensionless viscosity, $\eta^{*}$, for TOTM obtained in the present work was correlated with the molar volume by an equation of the form

$\frac{1}{\eta *}=\sum_{i=0}^{4} a_{i}\left(\frac{V_{\mathrm{m}}}{V_{0}}\right)^{i}$

Assael et al. [14] have also used a similar equation, but with four parameters instead of five as in Eq. (3). The fitting coefficients $a_{\mathrm{i}}$ of Eq. (3), RMSD and bias for the correlation, are listed in Table 4. The value of $V_{0}$ decreases slightly with the temperature, according to the empirical polynomial relation.

$V_{0} \times 10^{6}\left(\mathrm{~m}^{3} \mathrm{~mol}^{-1}\right)=l+m T+n T^{2}$

The coefficients $l, m$ and $n$ were obtained by simultaneous fitting of Eqs. (3) and (4) and are shown in Table 4. The values of the
RMSD and bias of the fitting, are defined as

$\operatorname{RMSD}=\left[\frac{1}{N} \sum_{i}^{N}\left(\frac{\eta_{\text {exp }, i}}{\eta_{\text {calc }, i}}-1\right)^{2}\right]^{1 / 2}$

bias $=\frac{1}{N} \sum_{i}^{N}\left(\frac{\eta_{\text {exp }, i}}{\eta_{\text {calc }, i}}-1\right)$

where $N$ is the total number of experimental data points, and the subscripts (exp,i and calc, $i$ ) stand for the $i$ th experimental and calculated data points, respectively.

In order to obtain the parameters of Eq. (4), a reference value for $V_{0}$ at an arbitrary temperature, $T_{\text {ref }}$, was calculated. In the present work we defined $T_{\text {ref }}=303.16 \mathrm{~K}$, which is the mean temperature of the lowest isotherm of the present set of viscosity measurements of TOTM. It is assumed that at $T_{\text {ref }}$ the value of $V_{0 \text {,ref }}$ is equivalent to the volume of the close-packing of the hard-spheres which can be calculated from the hard-sphere diameter, $\sigma_{\mathrm{HS}}[54]$.

$V_{0}=\frac{\sigma_{H S}^{3}}{2^{0.5}} N_{A}$

The hard-sphere diameter, $\sigma_{\mathrm{HS}}$, was calculated from the Lennard-Jonnes parameters, using the correlation proposed by Hammonds and Heyes [62]. The Lennard-Jones parameters were estimated by the correlations of Chung et al. [63,64], as described in Ref. [65]. The boiling temperature, $T_{\mathrm{b}}$, used was indicated by the supplier (Sigma-Aldrich) in ref [41]. The critical temperature, $T_{\mathrm{C}}$, and the critical volume, $V_{c}$, necessary for the estimation of the Lennard-Jones parameters, were obtained using the predictive method of Marrero and Pardillo [66], as described in Ref. [65]. The reference value for $V_{0}$ obtained at $T_{\text {ref }}=303.16 \mathrm{~K}$ is $462.4 \times 10^{-6}$ $\mathrm{m}^{3} \mathrm{~mol}^{-1}$.

Table 4

Fitting Parameters of Eqs. (3) and (4).

\begin{tabular}{ll}
\hline$l\left(\mathrm{~m}^{3} \mathrm{~mol}^{-1}\right)$ & 701.04494 \\
$m\left(\mathrm{~m}^{3} \mathrm{~mol}^{-1} \mathrm{~K}^{-1}\right)$ & -1.126479 \\
$n\left(\mathrm{~m}^{3} \mathrm{~mol}^{-1} \mathrm{~K}^{-2}\right)$ & $1.119602 \times 10^{-3}$ \\
$a_{0}$ & -0.193449 \\
$a_{1}$ & $5.073316 \mathrm{E}-01$ \\
$a_{2}$ & -0.4460009 \\
$a_{3}$ & 0.1332249 \\
$a_{4}$ & $-1.577519 \times 10^{-3}$ \\
RMSD (\%) & 0.53 \\
bias (\%) & 0.00 \\
\hline
\end{tabular}




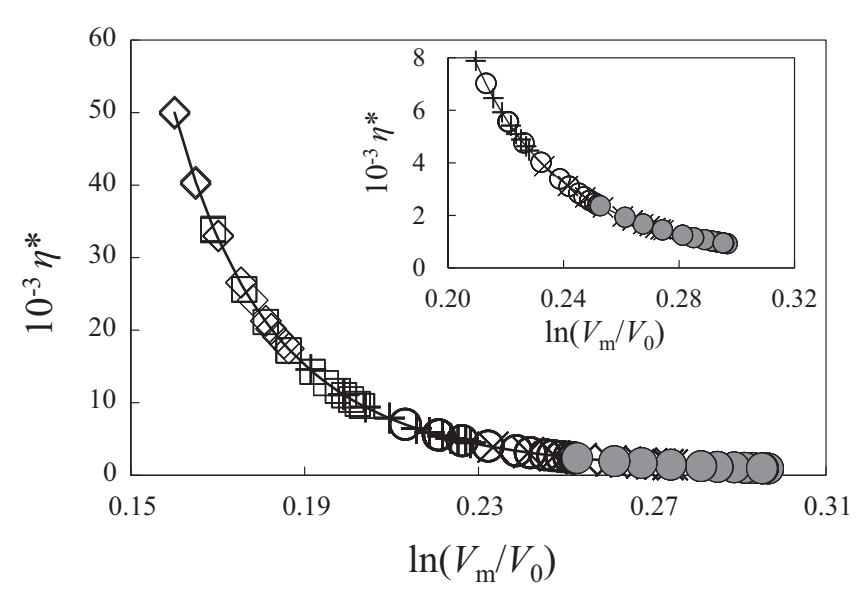

Fig. 3. Plot of the dimensionless viscosity, $\eta^{*}$, for TOTM as a function of $\ln \left(V_{\mathrm{m}} / V_{0}\right)$ along several isotherms. Calculated by Eq. (3) (-) and experimental: $\diamond, 303 \mathrm{~K}$; $\square$, $313 \mathrm{~K} ;+$ +, $328 \mathrm{~K} ; \bigcirc, 343 \mathrm{~K} ; \times, 358 \mathrm{~K} ; \bigcirc, 373 \mathrm{~K}$.

It is noteworthy that the viscosities measured in the present work span a large interval, ranging from about ( 9 to 463 ) $\mathrm{mPa}$. The quality factor [67] of the viscosity measurements changes from about (25 to 2 ). In order to deal with such a huge variation, the objective function to be minimized to fit all these data simultaneously has been defined as a sum of squares of the relative deviations of the experimental results from the fitting equation, as defined by the following function:

$\phi=\sum_{i=1}^{N}\left(\frac{\eta_{\exp , i}-\eta_{\text {calc }, i}}{\eta_{\exp , i}}\right)^{2}$

where $N$ is the total number of experimental data points. The correlation of the viscosity with the molar volume, was accomplished using MatLab ${ }^{\mathrm{TM}}$ software. The minimum of Eq. (8) was obtained by the function FMINSEARCH (multidimensional nonlinear minimization with a Nelder-Mead algorithm).

In Fig. 3, the experimental and calculated $\eta^{*}$ from Eqs. (3) and (4), respectively, are plotted as a function of $\ln \left(V_{\mathrm{m}} / V_{0}\right)$. The deviations of the fitting are shown in Fig. 4.

The RMSD of the correlation Eq. (3) is $0.53 \%$, and the bias is essentially zero. The maximum deviation of the viscosity data from the correlation does not exceed $\pm 1.7 \%$.

In Table 5 the viscosity values obtained by extrapolation of correlation of Eq. (3) to atmospheric pressure are shown for several

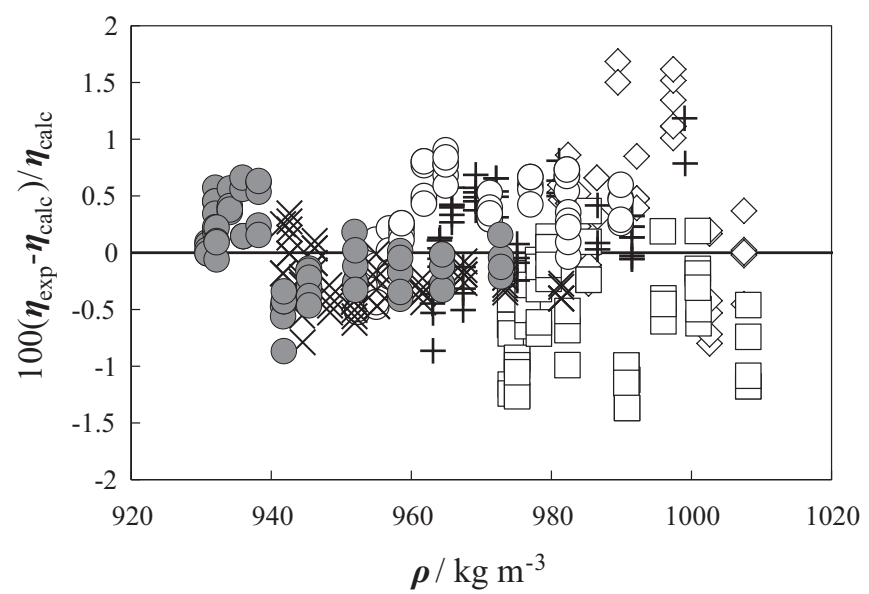

Fig. 4. Deviations of the vibrating wire TOTM viscosity data, from correlation Eq. (3), with parameters from Table 4 as a function of the density, for several isotherms: $\diamond, 303 \mathrm{~K} ; \square, 313 \mathrm{~K} ;+, 328 \mathrm{~K} ; \bigcirc, 343 \mathrm{~K} ; \times, 358 \mathrm{~K} ; \bigcirc, 373 \mathrm{~K}$.
Table 5

Viscosity values for TOTM obtained with the vibrating-wire technique, extrapolated to atmospheric pressure by means of Eq. (3) with parameters given in Table 4. Density values were obtained using Eq. (6) with parameters of Table 4, from part II of this work [42].

\begin{tabular}{lcc}
\hline$T(\mathrm{~K})$ & $\rho\left(\mathrm{kg} \mathrm{m}^{-3}\right)$ & $\eta(\mathrm{mPa})$ \\
\hline Extrapolated data for comparison with results by De Lorenzi et al. [68] \\
298.15 & 984.5 & $212.7^{\mathrm{a}}$ \\
308.16 & 977.1 & 114.3 \\
318.08 & 969.8 & 66.54 \\
328.96 & 961.9 & 39.71 \\
338.87 & 954.7 & 26.36 \\
348.72 & 947.5 & 18.39 \\
358.63 & 940.4 & 13.33 \\
368.46 & 933.4 & 10.02 \\
& & \\
Extrapolated data for comparison with capillary data from this work \\
303.17 & 980.8 & 154.2 \\
313.18 & 973.4 & 86.13 \\
323.10 & 966.1 & 51.94 \\
328.06 & 962.5 & 41.32 \\
\hline
\end{tabular}

a Value extrapolated also in the temperature, from (303.15 to 298.15) K.

temperatures. These values were used for the comparisons with viscosity data obtained in this work and by De Lorenzi et al. [68], both performed with Ubbelohde capillaries at atmospheric pressure.

\subsection{Viscosity measurements of TOTM using an Ubbelohde capillary viscometer}

Complementary measurements of the viscosity of tris(2ethylhexyl) trimellitate were performed using an Ubbelohde capillary viscometer at temperatures from about (303 to 328 ) K and at a pressure of $0.1 \mathrm{MPa}$. The results are shown in Table 6. At each temperature, $T$, the viscosity is the mean value of five measurements performed at temperatures differing less than $0.01 \mathrm{~K}$ from the mean temperature and $\pm 0.2 \%$ from the mean viscosity. For each temperature, the density, $\rho(\mathrm{T})$, was obtained using Eq. (6) with parameters of Table 4, from part II of this work [42].

\subsection{Comparison of viscosity results}

No viscosity data for tris(2-ethylhexyl) trimellitate above atmospheric pressure could be found in the literature. As a consequence, the viscosity results obtained in the present work using the vibrating wire technique have been extrapolated to atmospheric pressure by means of Eq. (3), in order to enable comparisons. Fig. 5 plots the relative deviations of our vibratingwire results with two sets of data obtained with Ubbelohde capillaries at atmospheric pressure. One of those sets has been published by De Lorenzi et al. [68] and the other was obtained in the present work. The extrapolated viscosity values used in the comparisons are presented in Table 4 evidencing a very good agreement with our own capillary data. The maximum relative

Table 6

Viscosity of TOTM measured with an Ubbelohde capillary viscometer at $0.1 \mathrm{MPa}$. Density values, $\rho(T)$, were obtained using Eq. (6) with parameters of Table 4, from part II of this work [42]. The water content before and after the measurements was (26 and 248) $\mathrm{mg} \mathrm{kg}^{-1}$.

\begin{tabular}{llc}
\hline$T(\mathrm{~K})$ & $\rho\left(\mathrm{kg} \mathrm{m}^{-3}\right)$ & $\eta(\mathrm{mPas})$ \\
\hline 303.17 & 980.8 & 153.9 \\
313.18 & 973.4 & 86.37 \\
323.10 & 966.1 & 52.41 \\
328.06 & 962.5 & 41.71 \\
\hline
\end{tabular}

Overall uncertainties: $U(T)= \pm 0.05 \mathrm{~K} ; U(\rho)= \pm 0.2 \% ; U(\eta)= \pm 1.5 \%$. 


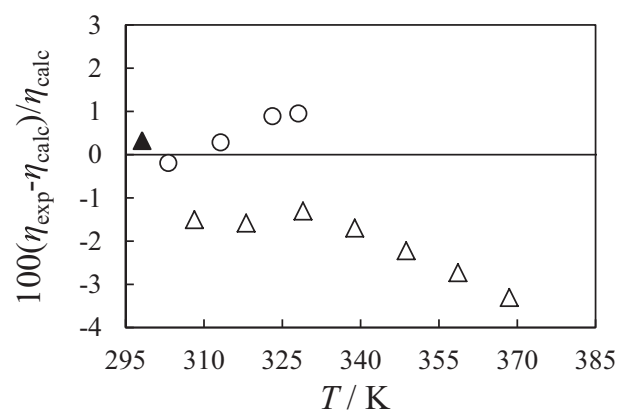

Fig. 5. Relative deviations of data obtained at atmospheric pressure from the present extrapolated viscosity data (in Table 5): this work, using an Ubbelohde capillary, shown in Table $6(\bigcirc)$; from De Lorenzi et al. [68] ( $\triangle$ [extrapolated only in pressure], $\boldsymbol{\Delta}$ [extrapolated in pressure and temperature], Ubbelohde capillary).

deviation is less than $\pm 1 \%$, which is within the uncertainties assigned to both methods. The data obtained by De Lorenzi et al. [68] agree with the present vibrating wire results within $\pm 2 \%$ for temperatures up to $339 \mathrm{~K}$, which is commensurate with the estimated uncertainty of the present vibrating wire measurements. However, for higher temperatures up to $368 \mathrm{~K}$ the deviations increase with increasing the temperature, reaching a maximum of $\pm 3.3 \%$. De Lorenzi et al. [68] report that their measurements were performed with a single Ubbelohde capillary. Taking into account the limited recommended measuring ranges of normalized Ubbelohde viscometers [69], this may explain their increased deviations from our results, encountered at the highest temperatures.

\section{Conclusions}

A new vibrating wire sensor and ancillary equipment for moderately high viscosity, at high pressures and temperatures up $373 \mathrm{~K}$, have been presented.

In response to an increasing demand of viscosity standards for high viscosity, at high pressures and high temperatures, the present article is aimed to propose TOTM as a plausible candidate for that purpose.

New viscosity results for tris(2-ethylhexyl) trimellitate (TOTM) were obtained using the new sensor in the range of about ( 9 to $460) \mathrm{mPa} s$, with a corresponding quality factor within (2-25), in a range of temperatures from (303 to 373 ) $\mathrm{K}$ and pressures up to $65 \mathrm{MPa}$. To the knowledge of the authors these are the first measurements of the viscosity of TOTM at pressures above atmospheric.

The comparisons of the vibrating wire viscosity data with viscosity data obtained at atmospheric pressure using an Ubbelohde capillary in this work were quite satisfactory, within $\pm 1 \%$. The comparisons with literature data, also obtained with an Ubbelohde capillary at atmospheric pressure, are within $\pm 2 \%$ for temperatures up to $339 \mathrm{~K}$ and within $\pm 3.3 \%$ for temperatures up to $368 \mathrm{~K}$.

\section{Acknowledgements}

This work was supported by the Strategic Projects PEst-OE/QUI/ UI0100/2011 and PEst-OE/QUI/UI0100/2013 all funded by Fundação para a Ciência e a Tecnologia (FCT), Portugal. The authors thank Casa Pia de Lisboa (CPL), Portugal, with special acknowledgements to the Executive Director of CPL, Bárbara Evangelista and to the CPL teacher Fernando Ribeiro for the construction of some parts of the vibrating wire sensor presented in this work, in the mechanical workshops of the institution. Thanks to the technical staff of Universidade Aberta, Portugal, for the professional execution and treatment of the vibrating wire sensor pictures presented in this paper. Thanks are also due to the Portuguese NMR network (IST node) for providing access to the facilities, and FCT for the funding of the NMR facility through RECI/QEQ-QIN/0189/2012. Furthermore, J.C.F.D. thanks FCT, Portugal, for his PhD grant (SFRH/BD/ $66736 / 2009)$.

\section{References}

[1] R. Kasameyer, D. Airey, J. Ratulowski, T. Goodwin, G. Mathews, K. Schmidt HPHT Viscosity Standards Workshop Executive Summary (Schlumberger, January 22, Stafford, Texas, USA, 2010). http://www.slb.com/ /media/Files core_pvt_lab/other/hpht_viscosity_standards_workshop_2010_summary.pdf, (accessed 14.05.2014)

[2] K. Schmidt, Viscosity Standards High-Pressure, High-Temperature, and High-Viscosity conditions (Schlumberger, January 22, Stafford, Texas, USA 2010). http://www.slb.com/ /media/Files/core_pvt_lab/other/viscosity_standards_for_hpht_and_high_viscosity_conditions.pdf, (accessed 14.05.2014).

[3] R. Kasameyer, D. Airey, J. Cole, Viscometer State-of-the-Art (Schlumberger, January 22, Stafford, Texas, USA, 2010). http://www.slb.com/ /media/Files/ core_pvt_lab/other/high_pressure_viscometers.pdf, (accessed 14.05.2014).

[4] D. Tapriyal1, R. Enick, M. McHugh, I.K. Gamwo, B. Morreale, High Temperature, High Pressure Equation of State Density Correlations and Viscosity Correlations. http://www.netl.doe.gov/File\%20Library/Research/onsite\%20research/ TRS-1-2012-EOS-rev0-20120824.pdf, (accessed 14.05.2014).

[5] H. Baled, D. Tapriyal, B.D. Morreale, Y. Soong, I. Gamwo, V. Krukonis, B.A Bamgbade, Y. Wu, M.A. McHugh, W.A. Burgess, R.M. Enick, Int J. Thermophys. 34 (2013) 1845-1864.

[6] M.J.P. Comuñas, X. Paredes, F.M. Gaciño, J. Fernández, J.P. Bazile, C. Boned, J.L. Daridon, G. Galliero, J. Pauly, K.R. Harris, M.J. Assael, S.K. Mylona, J. Phys. Chem. Ref. Data 42 (2013) 033101-1-033101-6.

[7] S.K. Mylona, M.J. Assael, K.D. Antoniadis, S.K. Polymatidou, L. Karagiannidis, J Chem. Eng. Data 58 (2013) 2805-2808.

[8] F.J.P. Caetano, J.M.N.A. Fareleira, A.P. Fröba, K.R. Harris, A. Leipertz, C.M.B.P. Oliveira, J.P. Martin Trusler, W.A. Wakeham, J. Chem. Eng. Data 53 (2008) 2003-2011.

[9] M.J.P. Comuñas, X. Paredes, F.M. Gaciño, J. Fernández, J.-P. Bazil, C. Boned, J.-L. Daridon, G. Galliero, J. Pauly, K.R. Harris, J. Chem. Thermodyn. 69 (2014) 201-208.

[10] S.K. Mylona, M.J. Assael, M.J.P. Comuñas, X. Paredes, F.M. Gaciño, J. Fernández, J. P. Bazile, C. Boned, J.L. Daridon, G. Galliero, J. Pauly, K.R. Harris, J. Phys. Chem. Ref. Data 43 (2014) 13104-1-13104-11.

[11] Project No.: 2012-051-1-100; Start date: 2013-05-15, International standard for viscosity at temperatures up to $473 \mathrm{~K}$ and pressures below 200MPa. http: / www.iupac.org/nc/home/projects/project-db/project-details.html? tx_wfqbe_pi1\%5Bproject_nr\%5D=2012-051-1-100, (accessed 14.05.2014).

[12] J.V. Sengers, J.T.R. Watson, J. Phys. Chem. Ref. Data 15 (1986) 1291-1314.

[13] J.H. Dymond, H.A. Oye, J. Phys. Chem. Ref. Data 23 (1994) 41-53.

[14] M.J. Assael, H.M.T. Avelino, N.K. Dalaouti, J.M.N.A. Fareleira, K.R. Harris, Int. J. Thermophys. 22 (2001) 789-799.

[15] F.J.V. Santos, C.A. Nieto de Castro, J.H. Dymond, N.K. Dalaouti, M.J. Assael, A. Nagashima, J. Phys. Chem. Ref. Data 35 (2006) 1-8.

[16] LTPEP, viscosity-fluids (topic: systems studied so far) http://transp.eng.auth gr/index.php/viscosity/visliq, (accessed 14.05.2014).

[17] M.J. Assael, H. Bauer, N.K. Dalaouti, K.R. Harris, Int. J. Thermophys. 25 (2004) $13-20$.

[18] F.J.P. Caetano, J.M.N.A. Fareleira, C.M.B.P. Oliveira, W.A. Wakeham, Int. J Thermophys. 25 (2004) 1311-1322.

[19] F.J.P. Caetano, J.M.N.A. Fareleira, C.M.B.P. Oliveira, W.A. Wakeham, J. Chem. Eng. Data 50 (2005) 1875-1878.

[20] F.J.P. Caetano, J.M.N.A. Fareleira, A. Fernandes, C.M.B.P. Oliveira, A.P. Serro, I.M Simões de Almeida, W.A. Wakeham, Fluid Phase Equilib. 245 (2006) 1-5.

[21] K.R. Harris, J. Chem. Eng. Data 54 (2009) 2729-2738.

[22] X. Paredes, O. Fandiño, M.J.P. Comuñas, A.S. Pensado, J. Fernández, J. Chem. Thermodyn. 41 (2009) 1007-1015.

[23] F. Peleties, J.J. Segovia, J.P.M. Trusler, D. Vega-Maza, Chem. Thermodyn. 42 (2010) 631-639.

[24] S. Brito e Abreu, H.M.N.T. Avelino, F.J.P. Caetano, João M.N.A. Fareleira, J. Chem. Eng. Data 55 (2010) 3525-3531.

[25] F. Peleties, J.P.M. Trusler, J. Chem. Eng. Data 56 (2011) 2236-2241.

[26] M.J. Assael, S.K. Mylona, J. Chem. Eng. Data 58 (2013) 993-1000.

[27] M.M. Al Motari, M.E. Kandil, K.N. Marsh, J. Chem. Eng. Data 52 (2007) 1233-1239.

[28] C. Nieto de Castro, J. Chem. Eng. Data 54 (2009) 171-178.

[29] X. Paredes, O. Fandiño, A.S. Pensado, M.J.P. Comuñas, J. Fernández, J. Chem. Thermodyn. 44 (2012) 38-43.

[30] K. Marsh, J.F. Brennecke, R.D. Chirico, M. Frenkel, A. Heintz, J.W. Magee, C.J. Peters, L.P.N. Rebelo, K.R. Seddon, Pure Appl. Chem. 81 (2009) 781-790.

[31] R.D. Chirico, V. Diky, J.W. Magee, M. Frenkel, K. Marsh, Pure Appl. Chem. 81 (2009) 791-828. 
[32] European Chemicals Agency, Candidate List of Substances of Very High Concern for Authorisation; http://echa.europa.eu/candidate-list-table/-/substance/364/search/+/del/75/col/INCLUSIONDATECL/type/desc/pre/2/view, (accessed 14.05.2014).

[33] J.C.F. Diogo, F.J.P. Caetano, J.M.N.A. Fareleira, W.A. Wakeham, Viscosity measurements on ionic liquids: a cautionary tale, Int. J. Thermophys. (2013), doi:http://dx.doi.org/10.1007/s10765-013-1487-y (published online 30 July 2013)

[34] K.R. Seddon, A. Stark, M.J. Torres, Pure Appl. Chem. 72 (2000) 2275-2287.

[35] ExxonMobil Biomedical Sciences Inc., High Production Volume (Hpv) Chemical Challenge Program Test Plan for the Trimellitate Category. http:/ www.epa.gov/hpv/pubs/summaries/trime/c13468tp.pdf EPA of USA (accessed 14.05.2014).

[36] OECD report, Tris(2-Ethylhexyl) Benzene-1,2,4-Tricarboxylate Cas $\mathrm{N}^{\circ}: 3319$ 31-1, Sids Initial Assessment Report For SIAM 14. http://www.chem.unep.ch/ irptc/sids/OECDSIDS/3319311.pdf, United Nations Environment Programme, (accessed 14.05.2014).

[37] http://www.diolube.com/Diolube\%20Trimellitate\%20Esters.htm, (accessed 23.09.2014).

[38] K. Kambia, T. Dine, R. Azar, B. Gressier, M. Luyckx, C. Brunet, Int. J. Pharm. 229 (2001) 139-146.

[39] S. Genay, C. Luciani, B. Décaudin, T. Nicolas Kambia, T. Dine, N. Azaroual, P. Di Martino, C. Barthélémy, P. Odou, Int. J. Pharm. 412 (2011) 47-51.

[40] A.S. Shehata, Z.A. El-Rehim Mohamed, M.R.A. El-Haleem, M.A. Samak, J. Clin. Toxicol. 3 (2013) 1-9.

[41] SIGMA Aldrich Safety data Sheet, MSDS, SAFETY DATA SHEET. http://www. sigmaaldrich.com/MSDS/MSDS/DisplayMSDSPage.do?country=PT\&language $=$ EN-generic $\&$ productNumber $=538140 \&$ brand $=$ ALDRICH\&PageToGoToURL=\%2Fsafety-center.html, (accessed 19.12.2013).

[42] J.C.F. Diogo, H.M.N.T. Avelino, F.J.P. Caetano, J.M.N.A. Fareleira, Tris(2-Ethylhexyl) trimellitate (TOTM) a potential reference fluid for high viscosity. Part II: density measurements at temperatures from (293 to 373) K and pressures up to $68 \mathrm{MPa}$, Fluid Phase Equilib. (2014), doi:http://dx.doi.org/10.1016/j.fluid.2014.10.003.

[43] A.A.H. Pádua, J.M.N.A. Fareleira, J.C.G. Calado, W.A. Wakeham, Rev. Sci. Instrum. 69 (1998) 2392-2399.

[44] T. Retsina, S.M. Richardson, W.A. Wakeham, Appl. Sci. Res. 43 (1986) 127-158.

[45] J.C.F. Diogo, F.J.P. Caetano, J.M.N.A. Fareleira, W.A. Wakeham, C.A.M. Afonso, C.S Marques, J. Chem. Eng. Data 57 (2012) 1015-1025.

[46] J.C.F. Diogo, F.J.P. Caetano, J.M.N.A. Fareleira, W.A. Wakeham, Fluid Phase Equilib. 353 (2013) 76-86.

[47] F.J.P. Caetano, J.M.N.A. Fareleira, C.M.B.P. Oliveira, W.A. Wakeham, J. Chem. Eng. Data 50 (2005) 201-205.

[48] A.A.H. Pádua, J.M.N.A. Fareleira, J.C.G. Calado, W.A. Wakeham, Int. J. Thermophys. 17 (1996) 781-802.
[49] J.L. Correia da Mata, J.M.N.A. Fareleira, C.M.B.P. Oliveira, F.J.P. Caetano, W.A. Wakeham, High Temp. -High Press. 33 (2001) 669-676.

[50] S.S. Chen, M.W. Wambsganss, J.A. Jendrzejczyk, Trans. ASME, Ser. E 43 (1976) 325-329.

[51] Newtonian viscosity standard specimen 20AW, ZMK. Zentrüm fur Messen und Kalibrieren-Analitik-GmbH, serial number 59, Calibration mark 04-1240/DK-15186-01-00/2013-07, Germany: Bitterfeld-Wolfen, 2013.

[52] C.M.B.P. Oliveira, Viscosity of Liquid Hydrocarbons at High Pressure. Ph.D. Thesis, Imperial College of Science Technology and Medicine, London, United Kingdom, 1991.

[53] J.C.F. Diogo, F.J.P. Caetano, J.M.N.A. Fareleira, Fluid Phase Equilib. 367 (2014) 85-94.

[54] S.F.Y. Li, R.D. Trengove, W.A. Wakeham, M. Zalaf, Int. J. Thermophys. 7 (1986) 273-284.

[55] J.H. Dymond, Chem. Soc. Rev. 14 (1985) 317-356.

[56] A.A.H. Pádua, J.M.N.A. Fareleira, J.C.G. Calado, W.A. Wakeham, J. Chem. Eng. Data 41 (1996) 1488-1494.

[57] A.A.H. Pádua, J.M.N.A. Fareleira, J.C.G. Calado, W.A. Wakeham, J. Chem. Eng. Data 41 (1996) 731-735.

[58] H.M.T. Avelino, J.M.N.A. Fareleira, W.A. Wakeham, Int. J. Thermophys. 24 (2003) 323-336.

[59] H.M.N.T. Avelino, J.M.N.A. Fareleira, C.M.B.P. Oliveira, J. Chem. Eng. Data 51 (2006) 1672-1677.

[60] H.M.N.T. Avelino, J.M.N.A. Fareleira, C.M.B.P. Oliveira, J. Chem. Eng. Data 53 (2008) 53-56.

[61] M.J. Assael, J.H. Dymond, M. Papadaki, P.M. Patterson, Int J. Thermophys 13 (1992) 269-281.

[62] K.D. Hammonds, D.M. Heyes, J. Chem. Soc. -Faraday Trans. 84 (1988) 705-725.

[63] T.-H. Chung, M. Ajlan, L.L. Lee, K.E. Starling, Ind. Eng. Chem. Res. 27 (1988) 671679 Cited in Ref. [65].

[64] T.-H. Chung, L.L. Lee, K.E. Starling, Ind. Eng. Chem. Fundam. 23 (1984) 8-13 Cited in Ref. [65].

[65] B.E. Poling, J.M. Prausnitz, J.P. O'Connell, The Properties of Gases and Liquids, Fifth ed., McGraw-Hill, New York, 2001.

[66] J. Marrero-Marejón, E. Pardillo-Fontdevila, AIChE J. 45 (1999) 615-621 Cited in Ref. [65].

[67] J.L. Correia da Mata, F.J.P. Caetano, C.M.B.P. Oliveira, J.M.N.A. Fareleira, J. Chem. Eng. Data 54 (2009) 2562-2568.

[68] L. De Lorenzi, M. Fermeglia, G. Torriano, J. Chem. Eng Data 43 (1998) 183-186.

[69] SI Analytics, Ubbelohde Viscometer and Micro-Ubbelohde Viscometer, Operating Instructions. http://www.si-analytics.com/fileadmin/upload/ Gebrauchsanleitungen/Viskosimeterie/Viskosimeter/Ubbelohde/UK/Ubbelohde\%20Viscometer\%20and\%20micro_200\%20KB_English-PDF.pdf (accessed 14.05.2014). 